\title{
REVERSIBILITY OF RENAL ATROPHY CAUSED BY UNILATERAL REDUCTION OF RENAL BLOOD SUPPLY*
}

\author{
By T. OMAE AND G. M. C. MASSON \\ (From the Research Division of the Cleveland Clinic Foundation, and the Frank E. Bunts \\ Educational Institute, Cleveland, Ohio)
}

(Submitted for publication June 30, 1959; accepted September 4, 1959)

Experimental unilateral reduction of renal blood flow results in atrophy of one kidney and hypertrophy of the other $(1-4)$. The atrophic process consists of involution of the glomeruli and transformation of the tubules into thick compact cords along with failure of excretory function. $\mathrm{Hy}-$ pertension is generally, but not necessarily, associated with unilateral partial atrophy (5); when it is present and severe, only the nonatrophic kidney shows nephrosclerosis (1-4). Remission of hypertension following restoration of renal blood flow or uninephrectomy depends on the extent of the secondary hypertensive changes in the contralateral kidney (6).

These manifestations constitute the experimental counterpart of those seen in clinical unilateral renal artery disease. Removal of the atrophic kidney is the treatment commonly advocated $(7,8)$. It occurred to us that if we could demonstate that a kidney atrophic, but otherwise devoid of lesions, could regain its normal excretory function, then it might be desirable to re-establish surgically its normal blood supply and if necessary to remove the contralateral kidney.

Two previous observations suggest that recovery of function may occur. In rats, unilateral curtailment of renal blood flow associated with simultaneous contralateral nephrectomy prevented renal atrophy in some of the animals (9). In dogs, a kidney anuric as a result of a clamp on the renal artery resumed urine formation after contralateral nephrectomy (10).

The purpose of the present investigations was to extend these studies to see whether renal atrophy can be prevented regularly by simultaneous contralateral nephrectomy and whether kidneys with various degrees of atrophy can recover equally well when the clamp is removed or left

* This investigation was supported in part by a grant (H-96) from the National Heart Institute, National Institutes of Health, Bethesda, Md. in place. We also observed the effects of these various manipulations on blood pressure.

\section{MATERIAL AND METHODS}

The procedure best suited for our purpose would have been one which regularly elicited a predictable degree of renal atrophy without necrosis and permitted easy removal of the constriction. Four methods were assessed: a loose nylon ligature around the aorta in very young rats (5); aortic constriction by silk thread in adult rats (1) ; use of silver clips on the aorta or on the renal artery $(2,6)$. We found that thread ligature gave a more reproducible degree of constriction but had the disadvantage of unavoidable fatal hemorrhages when release of the constriction was attempted; silver clips on aortae gave less predictable results but could be opened easily; constriction of an artery as small as the renal artery with clips was too capricious, although it permitted blood pressure measurements by tail plethysmography. For most of our experiments we adopted the procedure of aortic stenosis with silver clips.

Sprague-Dawley rats, weighing 40 to $80 \mathrm{Gm}$. were used; they were males or females since sex has no influence on the degree of renal atrophy (1). They were given tap water and fed Purina Fox Chow. Silver clips were prepared according to the method of Wilson and Byrom (6). From silver ribbon $(0.8 \mathrm{~mm}$. wide and $0.13 \mathrm{~mm}$. thick) which was annealed by careful heating over a gas burner, strips about $1 \mathrm{~cm}$. long were cut and bent carefully over the mandrel of a No. 18 gauge needle, which gave an opening with a diameter of $0.55 \mathrm{~mm}$. Following ether anesthesia and a midline incision, the aorta between the origins of the two renal arteries was dissected free with cotton pads; a clip was then hooked in this space and closed by twisting both ends together.

In one experiment "endocrine" kidneys were prepared according to the technique of Selye and Stone (1). Aortic constriction was produced in adult rats (130 to 160 Gm.) by a silk ligature which enclosed the artery and the mandrel of a No. 22 gauge needle $(0.25 \mathrm{~mm}$. diameter) which was subsequently withdrawn; ligature of the left ureter was done to ascertain absence of excretory function. Rats showing hydronephrosis at autopsy were discarded. Whether "endocrine" kidneys secrete excessive amounts of pressor substances (1) or, from morphologic observations (11), are deficient in antihypertensive principle is irrelevant; the fact remains that such atrophic kidneys cause an acute type of hypertension and vascu- 
lar disease, associated with cachexia and high mortality. Animals were kept after operation for periods up to 54 days. At the end of the experiment, blood was taken for blood urea nitrogen (BUN) determinations. Blood pressure was measured by tail plethysmography in rats in which the aortic clip was removed (12); in the others, hypertension was ascertained at the end of the experiment either by direct measurement in the carotid artery under light ether anesthesia or on the basis of cardiac ventricular hypertrophy. The results from these three methods are sufficiently accurate to provide comparative information on normotensive or hypertensive states: tail pressure correlates closely with carotid pressure (12) and changes in cardiac ventricular weights expressed in percentage of body weight parallel those in tail pressure (13).

At autopsy, kidneys and hearts were removed, fixed in Susa fluid, dissected and weighed; hearts were weighed after removal of auricles; sections were stained with periodic acid-fuchsin (PAS). Weights of organs were expressed in percentage of body weight at the time of removal. Since both kidneys from the same animal had nearly the same weight, we used the ratio left kidney/ right kidney as an index of differential weight between the two kidneys; this ratio will be referred to as the kidney ratio. Keeping in mind that renal atrophy was always elicited on the left side, a decrease in ratio will reflect atrophy of the left kidney and/or hypertrophy of the right kidney; conversely an increase in ratio will indicate hypertrophy of the left kidney and/or atrophy of the right kidney. Interpretation of the ratio will depend on comparison with suitable controls.

\section{EXPERIMENTAL PROCEDURE AND RESULTS}

1. Effects of uninephrectomy and unilateral "endocrine kidney" on the contralateral kidney

These preliminary experiments were carried out for the following purposes: first, to ascertain the variability of the normal kidney ratio in our strain of rats; secondly, to determine the degree of compensatory hypertrophy resulting from unilateral nephrectomy and lastly, using rats with "endocrine kidney" to determine whether renal hypertrophy is solely dependent on excretory function of the contralateral kidney.

Thirty rats weighing 130 to $160 \mathrm{Gm}$. were divided into three groups : animals of Group I were controls, those of Group II were uninephrectomized, and those of Group III were operated upon as described in the "endocrine kidney" technique. Groups II and III were sacrificed seven days later. The results (Table I) show that in normal rats there is a high degree of uniformity in the weight of each kidney which is reflected in the value of the kidney ratio of 0.99 . Uninephrectomy of seven days' duration elicits a statistically significant compensatory hypertrophy; the weight of the right kidney increased from 0.47 to $0.56 \mathrm{Gm}$. giving a kidney ratio of 0.83 . Heart weight was unchanged. The 12 rats subjected to the "endocrine kidney" procedure lost weight from a mean value of 147 to $114 \mathrm{Gm}$. At autopsy, nine rats showed typical "endocrine" left kidneys without hydronephrosis or necrosis. Macroscopic nephrosclerosis was seen in four rats, but only in the right kidney; cardiac necrosis and hemorrhages appeared in three animals; all the rats showed microscopic nephrosclerosis. There was about 33 per cent atrophy of the left kidney ( 0.31 to compare with $0.47 \mathrm{Gm}$. in controls) and a corresponding hypertrophy of the right kidney; this inverse relationship gave a kidney ratio of 0.49 . Hypertrophy on the right side was significantly greater

TABLE I

Effects of uninephrectomy and unilateral "endocrine kidney" on contralateral renal hypertrophy

\begin{tabular}{|c|c|c|c|c|c|}
\hline \multirow[b]{2}{*}{ Groups } & \multirow[b]{2}{*}{ Procedure } & \multicolumn{2}{|c|}{ Kidney* } & \multirow{2}{*}{$\begin{array}{l}\text { Kidney } \\
\text { ratio† } \\
\text { left/right } \\
\pm \text { S.E. }\end{array}$} & \multirow[b]{2}{*}{ Heart wt. $\dagger \pm$ S.E. } \\
\hline & & Right & Left & & \\
\hline I & & $\begin{array}{c}0.47 \\
(0.40-0.55)\end{array}$ & $\begin{array}{c}0.46 \\
(0.40-0.54)\end{array}$ & $\begin{array}{l}0.99 \\
\pm 0.009\end{array}$ & $\begin{array}{c}\text { Gm./100 Gm. body wt. } \\
0.36 \\
\pm 0.007\end{array}$ \\
\hline II & $\underset{\text { left }}{\text { Uninephrectomy }}$ & $\begin{array}{c}0.56 \\
(0.49-0.62)\end{array}$ & $\begin{array}{l}0.47 \\
(0.44-0.53)\end{array}$ & $\begin{array}{c}0.83 \\
\pm 0.024\end{array}$ & $\begin{array}{c}0.35 \\
\pm 0.009\end{array}$ \\
\hline III & $\begin{array}{c}\text { "Endocrine kidney" } \\
\text { left }\end{array}$ & $\begin{array}{l}0.63 \\
(0.58-0.70)\end{array}$ & $\begin{array}{c}0.31 \\
(0.27-0.37)\end{array}$ & 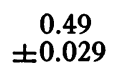 & $\begin{aligned} & 0.45 \\
\pm & 0.022\end{aligned}$ \\
\hline
\end{tabular}

* Mean and range.

$\dagger$ Mean and standard error of the mean. 
TABLE II

Effects of releasing aortic stenosis and uninephrectomy on kidney and heart weights - (20 days after clamping)

\begin{tabular}{|c|c|c|c|c|c|c|c|}
\hline \multirow{2}{*}{$\begin{array}{l}\text { Groups } \\
\text { and } \\
\text { no. of } \\
\text { animals }\end{array}$} & \multicolumn{4}{|c|}{ Operative procedure on day } & \multirow{2}{*}{$\begin{array}{c}\text { Kidney } \\
\text { ratiot } \\
\text { left/right } \\
\pm \text { S.E. }\end{array}$} & \multirow{2}{*}{$\begin{array}{l}\text { Heart wt. }{ }^{\dagger} \\
\pm \text { S.E. }\end{array}$} & \multirow[b]{2}{*}{ BUN $\ddagger$} \\
\hline & $1^{*}$ & 20 & 27 & 34 & & & \\
\hline & & & & & & $\begin{array}{l}\text { Gm. per } 100 \\
\text { Gm. body wt. }\end{array}$ & $m g . / 100 \mathrm{ml}$. \\
\hline $\begin{array}{l}I \\
41\end{array}$ & & Killed & & & $\begin{array}{c}0.76 \\
\pm 0.023\end{array}$ & $\begin{array}{c}0.45 \\
\pm 0.012\end{array}$ & $\begin{array}{c}20.1 \\
(11-38)\end{array}$ \\
\hline $\begin{array}{c}\text { II } \\
5\end{array}$ & & Unclamping & Killed & & $\begin{array}{c}0.80 \\
\pm 0.046\end{array}$ & $\begin{array}{r}0.43 \\
\pm 0.02\end{array}$ & $\begin{array}{c}13.9 \\
(11-19)\end{array}$ \\
\hline $\mathrm{III}_{5}$ & & Unclamping & $\begin{array}{l}\text { Right } \\
\text { nephrectomy }\end{array}$ & Killed & $\begin{array}{c}1.10 \\
\pm 0.052\end{array}$ & $\begin{array}{c}0.43 \\
\pm 0.031\end{array}$ & $\begin{array}{c}12.9 \\
(11-15)\end{array}$ \\
\hline $\begin{array}{c}\text { IV } \\
7\end{array}$ & & $\begin{array}{l}\text { Unclamping } \\
\text { + right } \\
\text { nephrectomy }\end{array}$ & Killed & & $\begin{array}{c}0.98 \\
\pm 0.056\end{array}$ & $\begin{array}{c}0.43 \\
\pm 0.023\end{array}$ & $\begin{array}{c}22.0 \\
(11-53)\end{array}$ \\
\hline $\begin{array}{l}\mathrm{V} \\
12\end{array}$ & & $\begin{array}{l}\text { Right } \\
\text { nephrectomy }\end{array}$ & Killed & & $\begin{array}{r}0.99 \\
\pm 0.035\end{array}$ & $\begin{array}{c}0.43 \\
\pm 0.011\end{array}$ & $\begin{array}{c}30.0 \\
(24-41)\end{array}$ \\
\hline $\begin{array}{l}\text { VI } \\
12\end{array}$ & & $\begin{array}{l}\text { Left } \\
\text { nephrectomy }\end{array}$ & Killed & & $\begin{array}{l}0.59 \\
\pm 0.033\end{array}$ & $\begin{array}{c}0.36 \\
\pm 0.009\end{array}$ & $\begin{array}{c}25.9 \\
(19-33)\end{array}$ \\
\hline $\begin{array}{l}\text { VII } \\
10\end{array}$ & $\begin{array}{l}\text { Right } \\
\text { nephrectomy }\end{array}$ & Killed & & & $\begin{array}{ll} & 1.12 \\
\pm & 0.038\end{array}$ & $\begin{array}{c}0.44 \\
\pm 0.007\end{array}$ & \\
\hline
\end{tabular}

* Aortic clamping was performed in all groups.

$\dagger$ Mean and standard error of the mean.

$\ddagger$ Mean and range.

$(p<0.05)$ than after uninephrectomy; this was probably due to early nephrosclerosis which is associated with accumulation of tubular casts before severe cellular atrophy or other degenerative changes take place. The marked increase in heart weight provides another evidence of high blood pressure.

\section{Effects of release of aortic constriction alone or in association with unilateral nephrectomy}

A. Twenty days of aortic constriction. The purpose of this experiment was to see whether unilateral renal atrophy due to aortic stenosis could be prevented by simultaneous contralateral nephrectomy, or reversed 20 days later by release of the constriction alone or in association with contralateral nephrectomy. The general plan as well as the operative procedures and results are outlined in Table II. One hundred fifty rats of both sexes were divided into seven groups and subjected to aortic stenosis (Groups I through VI) and to aortic stenosis plus right nephrectomy (Group VII). On the twenty-first postoperative day, animals of Groups I and VII were sacrificed.
Further operations as scheduled (Table II) were carried out only in those animals demonstrating on the operating table atrophy and lack of necrosis of the left kidney; 13 per cent of the survivors were discarded. Whenever release of the constriction (Groups II to IV) on the twenty-first day resulted in severe hemorrhages, such animals were sacrificed and the data added to those of the control, Group I. The experiment was terminated seven days after the last surgical intervention, since this period of time from the previous experiment was sufficient to permit significant compensatory renal hypertrophy.

Mortality for Groups I through VI following aortic stenosis amounted to 20 per cent. This was not increased by simultaneous right nephrectomy: in Group VII only one out of 11 rats died. Following nephrectomy and/or release of the clamp, mortality varied between zero and 17 per cent, except in Group IV (release of the constriction plus simultaneous right nephrectomy) where it reached the value of 46 per cent. Overall mortality and discards because of renal necrosis amounted to 46 per cent of the animals. 
Comparison of normal BUN values (mean 15.9, range 13 to $19.4 \mathrm{mg}$. per $100 \mathrm{ml}$.) with those obtained in various groups showed a slight but definite increase in Groups I, IV, V and VI. Opening of the clamp was sufficient to bring BUN values to normal (13.9 $\mathrm{mg}$. to compare with 20.1 $\mathrm{mg}$. per $100 \mathrm{ml}$. in Group I) but not when associated with simultaneous right nephrectomy (Group IV). However, when right nephrectomy was postponed by seven days, BUN values remained normal.

Aortic constriction (Group I) resulted, as in the preceding experiment with the "endocrine kidney," in a kidney ratio of less than one which was not altered by release of the constriction (Group II). When right nephrectomy was performed at the time of unclamping (Group IV) or seven days later (Group III), the atrophic kidney enlarged and kidney ratios became equal to or greater than one. There was no statistical difference between Groups III and IV. When right nephrectomy was performed without touching the clamp (Group $\mathrm{V}$ ), the kidney ratio was almost equal to one, indicating that kidney hypertrophy can occur in spite of partial obstruction to renal blood supply. This conclusion was confirmed by the results in Group VII in which right nephrectomy was performed at the time of aortic constriction; the left kidney not only did not atrophy but actually increased its size, with a resulting kidney ratio of 1.12. The ratio of 0.56 obtained in Group VI merely indicates that removal of a kidney made atrophic by aortic clamping can elicit further compensatory hypertrophy, presumably because some excretory function remained. Incidentally, in a few rats of Group I, the left kidney was larger than the right giving individual ratios greater than one (one of them was 1.3) in comparison with a mean ratio of 0.76 for the group; in these instances the right kidney was severely nephrosclerotic.

Heart weight values (Table II) were greater than 0.43 in all the groups except in Group VI where it was normal and equal to 0.36 . This is in agreement with results of blood pressure determinations. Normal values were obtained in Group VI (mean 110, range 105 to $120 \mathrm{~mm}$. Hg); in the other groups values were mostly over 150 $\mathrm{mm}$. $\mathrm{Hg}$ and as high as $200 \mathrm{~mm}$. $\mathrm{Hg}$.

The localization and nature of the lesions have been amply documented by studies on rats with "endocrine kidneys" $(1,2)$. Except for evidence of hypertensive vascular disease in all groups, histologic examinations were not informative. We could not detect any change suggesting healing in Group VI where hypertension remitted, probably because of the short period of observation. In this group, lesions of arteritis or arteriolar necrosis were present in the heart or right kidney of six rats; however, there was none in the pancreatic or mesenteric blood vessels. It is worth noting that these lesions did not prevent the fall in pressure subsequent to left nephrectomy.

Since the period of observation after unclamping or uninephrectomy may have been too short to evaluate the complete effects of these procedures, we have, in the following experiments, extended the period from 7 to 20 days. Aortic stenosis was performed in 60 rats which were divided into five groups. Groups I and II were controls and were sacrificed, respectively, on the twentieth and fortieth days. The other groups were subjected on the twentieth day to the following operative procedures: unclamping (Group III), unclamping plus right nephrectomy (Group IV), and unclamping plus left nephrectomy (Group V). The experiment was terminated on the fortieth day. The results obtained were in agreement with the previous ones. In short, renal atrophy was more pronounced after 40 than after 20 days, as indicated by the respective values of kidney ratios of 0.65 and 0.76 ; unclamping did not alter the ratio (0.63), while simultaneous right nephrectomy increased its value to 1.16 . The only other significant observation was the high heart weight (mean 0.41 ) following unclamping as compared with the normal value (mean 0.34) following removal of the atrophic kidney. Histologic examination showed that after unclamping and right nephrectomy, there was complete restoration of renal morphology so that the left kidney could not be distinguished from a normal kidney which had undergone compensatory hypertrophy.

$B$. Forty days of aortic constriction. The purpose of this experiment was similar to that of the previous one; the difference was in extension from 20 to 40 days of the period following aortic stenosis, in order to produce chronic renal atrophy (Table III). One hundred forty-seven rats were divided into five groups and subjected to aortic stenosis alone (Groups I to IV) or in association 
TABLE III

Effects of releasing aortic stenosis and uninephrectomy on kidney and heart weights (40 days after clamping)

\begin{tabular}{|c|c|c|c|c|c|c|}
\hline \multirow{2}{*}{$\begin{array}{l}\text { Groups } \\
\text { and } \\
\text { no. of } \\
\text { animals }\end{array}$} & \multicolumn{4}{|c|}{ Operative procedure on day } & \multirow{2}{*}{$\begin{array}{c}\text { Kidney } \\
\text { ratiơ } \\
\text { left/right } \\
\pm \text { S.E. }\end{array}$} & \multirow[b]{2}{*}{ Heart wt. $\dagger$} \\
\hline & $1^{*}$ & 40 & 47 & 54 & & \\
\hline $\begin{array}{c}\text { I } \\
33\end{array}$ & & Killed & & & $\begin{array}{c}0.68 \\
\pm 0.026\end{array}$ & $\begin{array}{c}\text { Gm. per } 100 \\
\text { Gm. body wt } \\
0.37 \\
\pm 0.009\end{array}$ \\
\hline $\begin{array}{l}\text { II } \\
12\end{array}$ & & Unclamping & Killed & & $\begin{array}{ll} & 0.76 \\
\pm & 0.107\end{array}$ & $\begin{array}{c}0.40 \\
\pm 0.016\end{array}$ \\
\hline $\begin{array}{l}\text { III } \\
9\end{array}$ & & Unclamping & $\begin{array}{l}\text { Right } \\
\text { nephrectomy }\end{array}$ & Killed & $\begin{array}{c}0.90 \\
\pm 0.050\end{array}$ & $\begin{array}{c}0.38 \\
\pm 0.019\end{array}$ \\
\hline $\begin{array}{l}\text { IV } \\
7\end{array}$ & & $\begin{array}{l}\text { Unclamping + } \\
\text { right } \\
\text { nephrectomy }\end{array}$ & Killed & & $\begin{array}{c}0.91 \\
\pm 0.013\end{array}$ & $\begin{array}{c}0.40 \\
\pm 0.010\end{array}$ \\
\hline $\begin{array}{l}V \\
14\end{array}$ & $\begin{array}{l}\text { Right } \\
\text { nephrectomy }\end{array}$ & Killed & & & $\begin{array}{c}1.03 \\
\pm 0.027\end{array}$ & $\begin{array}{c}0.39 \\
\pm 0.007\end{array}$ \\
\hline
\end{tabular}

* Aortic constriction was performed in all groups on the first day.

$\dagger$ Mean and standard error of the mean.

with right nephrectomy (Group V). On the fortieth day Groups I and V were sacrificed; the rats of the remaining groups (less 12 per cent discarded for renal necrosis) were operated as scheduled and sacrificed seven days after the last intervention.

Mortality during the first 40 days was 29 per cent in the groups with aortic stenosis alone; in Group V in which the animals had also right nephrectomy, mortality was 22 per cent. Subsequent surgical intervention in Groups II and IV resulted, respectively, in a mortality of 14,17 and 42 per cent; this relative proportion corresponds to that obtained in similar groups of the 20 day experiment. BUN values were so widespread as to be noninformative.

The results on kidney ratios (Table III) show complete agreement with those obtained in the 20 day experiment. In the control, Group I, it was equal to 0.68 . In some of the rats, the left kidney weighed only about $140 \mathrm{mg}$. per $100 \mathrm{Gm}$. of body weight with a corresponding value of $640 \mathrm{mo}$. for the right. Opening of the clamp (Group II) had no statistically significant effect but simultaneous (Group IV) or delayed (Group III) right nephrectomy increased the ratio to 0.91 and 0.90 , respectively. The highest ratio (1.03) was obtained in Group V, where aortic clamping was associated with simultaneous right nephrectomy.
Heart weights (Table III) and blood pressure were only slightly elevated and differences between groups were not statistically significant. The contrast between these results and those of the 20 day experiment, can be explained by the fact that during the period of 40 days following aortic stenosis, more rats, not included in the table, developed severe hypertensive vascular disease and died. Therefore, only mild or no lesions in the renal and extrarenal vascular bed were seen in the survivors. Another observation was that the left kidney of the rats which died following right nephrectomy (Groups III and IV) was still atrophic with marked interstitial fibrosis and casts in the few functioning nephrons. Evidently such a kidney was too involuted and diseased to take over the excretory function of the contralateral kidney.

\section{DISCUSSION}

Under uniform conditions, total renal mass, which is equally distributed between both kidneys, tends to remain constant (14) so that unilateral atrophy such as that produced by clamping of the renal artery is accompanied by contralateral compensatory hypertrophy (2). This results in a new equilibrium between the two kidneys which is not altered by removal of the clamp. When the hypertrophic kidney is removed, the contralateral 
atrophic kidney increases in size and regains its function, even when the clamp is left in place. This is demonstrated by the present experiments in which uninephrectomy was performed at the same time as, or 20 to 40 days after, contralateral reduction of renal blood flow, and is in accord with previous findings in dogs (10) and rats (9). However, absence of compensatory hypertrophy has also been reported in 5 of 14 rats (9) and in young rabbits (15) in which thread was used as constricting material. These discrepancies may be explained by the observation (5) that a loose nylon ligature around the aorta in young rats results during body growth in a progressive and almost complete involution of the left kidney without evidence of hypertension. Presumably the blood supply to this kidney, being gradually decreased, is barely enough to maintain the integrity of renal tissue and is therefore insufficient to permit hypersecretion of pressor substances or compensatory hypertrophy. Since gradual and complete renal involution was not observed with silver clips, one could assume that the physical nature of the constricting material (such as elasticity, width) is of critical importance.

The nature of the stimulus responsible for compensatory hypertrophy is unknown. The hypothesis which takes into account most of the pertinent observations has been proposed by Braun-Menendez (16). In short, kidney growth is regulated by protein metabolites (renotrophins) which are normally destroyed by the kidney; following reduction in renal mass, they accumulate and stimulate renal growth until a new equilibrium is reached. The mitosis-stimulating factor found in blood following uninephrectomy in rats may be renotrophin (17). That the kidney could inactivate its own secretions has been demonstrated with renin (18). According to this hypothesis, hypertension develops whenever a kidney cannot increase its size in order to maintain renotrophins at their normal levels. From this it is assumed that an atrophic kidney, resulting from renal artery clamping cannot hypertrophy. The present experiments disprove this assumption, but suggest that an unclamped kidney is more responsive than a clamped kidney to the same renotrophic stimulus.

Although aortic stenosis resulted generally in a kidney ratio left/right smaller than one, we found a few cases in which the left kidney was larger than the right. In such animals, the left had a normal appearance while the right was contracted and nephrosclerotic. Having eliminated anatomical anomalies, we assumed that the following events took place: aortic clamping elicited atrophy of the left kidney and severe hypertension which in turn produced nephrosclerosis of the unprotected right kidney; the ensuing loss of functioning tissue resulted in contraction of this kidney and secondarily in hypertrophy of the atrophic kidney. Since the left hypertrophied kidney remained structurally normal, the factor responsible for hypertrophy is different from the one causing nephrosclerosis. These observations also demonstrate that renal artery clamping protects the kidney against high blood pressure without interfering with renotrophic effects.

Release of the aortic constriction did not usually bring back blood pressure to normal levels as evidenced by heart weight. The lack of reliability of plethysmographic values in this situation was demonstrated by the impossibility, particularly in the 40 day experiment, in registering heart beats from the tail of some animals, suggesting persistent partial obstruction due to tissue proliferation (6). Considering heart weights greater than 0.40 $\mathrm{Gm}$. per $100 \mathrm{Gm}$. of body weight as indexes of hypertension, we found that between 40 and 75 per cent of the rats were still hypertensive after release of aortic constriction. On the other hand, following removal of the atrophic kidney, the percentage of animals remaining hypertensive was less than 10 per cent. The most obvious explanations for the persistence of hypertension are presence of vascular lesions in the contralateral kidney and in the extrarenal arterial bed, and persistence of mechanical obstructions in the aorta (19). Pieces of aorta removed for histologic examination were unfortunately lost. Indeed, a slight obstruction may be sufficient to maintain hypertension without marked interference with normal renal function as demonstrated in dogs by Corcoran and Page (20).

\section{SUM M ARY}

1. Unilateral renal atrophy was elicited in young rats by partial constriction of the aorta between the origins of the two renal arteries with silver clips. This was associated with uninephrec- 
tomy, unclamping, or a combination of the two procedures. Effects on kidney weight were expressed by the kidney ratio, left kidney/right kid$n e y$, which in normal rats is equal to one.

2. Aortic stenosis alone resulted 20 and 40 days later in a kidney ratio of 0.76 and 0.68 , respectively.

3. Right nephrectomy performed simultaneously with aortic stenosis did not increase the mortality over aortic stenosis alone. Left renal atrophy was prevented as shown by kidney ratios greater than one.

4. Removal of the clamp, 20 to 40 days after aortic stenosis, did not alter the kidney ratio. However, right nephrectomy caused hypertrophy of the left kidney, even when the clamp was left in place. The degree of atrophy did not influence recoverability as long as there were no degenerative lesions.

5. Unilateral renal atrophy was usually but not necessarily accompanied by hypertension. Left nephrectomy was more effective in remitting hypertension than removal of the clamp.

\section{REFERENCES}

1. Selye, H., and Stone, H. Pathogenesis of the cardiovascular and renal changes which usually accompany malignant hypertension. J. Urol. (Baltimore) 1946, 56, 399.

2. Pellegrini, G. The experimental ischemia of the kidney. Sci. med. ital. 1951, 2, 404.

3. Pickering, G. W., and Prinzmental, M. Experimental hypertension of renal origin in the rabbit. Clin. Sci. 1938, 3, 357.

4. Bohle, A. Kritischer Beitrag zur Morphologie einer endokrinen Nierenfunktion und deren Bedeutung für den Hockdrück. Arch. Kreisl.-Forsch. 1953, 20, 193.

5. Robert, A. Production d'une atrophie progressive du rein. Rev. canad. Biol. 1954, 13, 3.

6. Wilson, C., and Byrom, F. B. The vicious circle in chronic Bright's disease. Experimental evidence from hypertensive rat. Quart. J. Med. 1941, 10, 65.
7. Poutasse, E. F., and Dustan, H. P. Urologic causes of hypertension; hypertension due to renal artery lesions. Cleveland Clin. Quart. 1956, 23, 3.

8. Gellman, D. D. Reversible hypertension and unilateral renal artery disease. Quart. J. Med. 1958, 27, 103.

9. Block, M. A., Wakim, K. G., and Mann, F. C. Appraisal of certain factors influencing compensatory renal hypertrophy. Amer. J. Physiol. 1953, 172 , 60.

10. Surtshin, A., and Latorre, G. Effects of contralateral nephrectomy on renal function depressed by previous unilateral renal arterial constriction. Amer. J. Physiol. 1955, 182, 524.

11. Simonsen, M. The endocrine kidney. Acta path. microbiol. scand. 1950, 27, 520.

12. Del Greco, F., Olmsted, F., Masson, G. M., and Corcoran, A. C. Graphic measurement of arterial pressure in the unanesthetized rat; an improved method. J. Lab. clin. Med. 1953, 41, 729.

13. Hall, O., Hall, C. E. and Ogden, E. Cardiac hypertrophy in experimental hypertension and its regression following reestablishment of normal blood pressure. Amer. J. Physiol. 1953, 174, 175.

14. Braun-Menendez, E. Hypertension and relation between body weight and kidney weight. Acta physiol. lat.-amer. 1952, $2,2$.

15. Drury, D. R. Production of renal insufficiency by surgical procedure. Proc. Soc. exp. Biol. (N. Y.) 1932, 29, 856.

16. Braun-Menendez, E. Evidence for renotrophin as a causal factor in renal hypertension. Circulation 1958, 17, 696.

17. Ogawa, K., and Nowinski, W. W. Mitosis stimulating factor in serum of unilaterally nephrectomized rats. Proc. Soc. exp. Biol. (N. Y.) 1958, 99, 350.

18. Friedman, M., Selzer, A., and Sampson, J. J. Observations concerning the pressor substance present in the ischemic kidney blood of the dog. Amer. J. Physiol. 1941, 131, 799.

19. Floyer, M. A. The effect of nephrectomy and adrenalectomy upon the blood pressure in hypertensive and normotensive rats. Clin. Sci. 1951, 10, 405.

20. Corcoran, A. C., and Page, I. H. Renal blood flow in experimental hypertension. Amer. J. Physiol. 1942, 135, 361. 